\title{
Business communication style as a factor in the design of a digital employee in education
}

\author{
Anton Ivaschenko, Ekaterina Kolesnikova*, Tatiana Nikiforova, and Iulia Vasilieva
}

Samara State Technical University, 443100, Samara, Russia

\begin{abstract}
The problems of digital transformation as the main trend in the development of education and it's connection with the educational ecosystem are discussed. The transformation of the role of the teacher in the university in connection with the digitalization of society is noted. The place of the digital employee as an element of the social component of the ecosystem is indicated. The approaches to the design of the image of a digital employee are characterized: from the point of view of the components of the educational environment, the students' perceptions of the teacher as a partner in educational interactions and the peculiarities of business communication in joint activities. Style features take into account the integration of both external and internal human resources, and are formed by arbitrary selection from a set of potential components of the style. In the aspect of comfortable interaction, students' ideas about a comfortable teacher are analyzed. The study involved students with different periods of study at the university. Dispersion analysis revealed differences in ideas about a comfortable teacher, both of an affirmative supervenience and non-adaptive, requiring additional attention in organizing the educational process. Correlation analysis revealed the connection between personality traits and the coefficient showing the divergence between one's own style and the style of a comfortable teacher. The options for designing a digital teacher by distributing functions between a robot and a human are discussed. Recommendations are indicated that can be applied both for real university teachers and digital employees.
\end{abstract}

\section{Introduction}

Recently, many changes in society are associated with the processes of digitalization. Digital transformation is carried out as an acceleration and improvement of production processes through the introduction of special agents - (robots, artificial intelligence, partially or completely replacing the functions of a human being executor [1].

Digital transformation requires an integrated approach to the use of information technology in all processes of the organization. Moreover, not only within the organization, but also in its interaction with the world around, customers, partners and the state.

Developing digital enterprises and organizations are changing the tasks of personnel training, which is especially true for a modern higher educational institution. Classical

\footnotetext{
* Corresponding author: kolesnikovaei@yandex.ru
} 
education is being transformed towards voluntariness, duration (lifelong learning), and personalization of requests. In general, the understanding of the goals and objectives of the university is changing.

As P. Luksha describes in his study, a modern university appears as a digital ecosystem. Bringing together learners and the community to develop individual and collective potential, educational eco-systems correspond with major modern digitalization trends [2]. Namely, establishing a balance between the «analog» and «digital» worlds: reducing the negative impact of digital reality on the individual and collective psyche. Education is designed to correspond with the digitalization of the economy and society, to integrate new social and economic challenges into the educational process and educational environment. This is a «smart» human-centered technological environment: smart homes, cities, home and outdoor robots, the Internet, intensive use of artificial intelligence or artificial agents («personal assistants» for everyone), hybrid reality (real combined with supplemented and virtual). Therefore, educational ecosystems are shifting to a completely different learning model, which is replacing industrial / mechanistic approaches [2].

In such conditions, the teacher's activity acts as an «agent of change». Discussing the role and place of the teacher in the educational ecosystem, we note that the main attention of scientists and experts is now attracted to technical re-equipment, as well as training teachers to work in a digital environment in the field of instrumental skills [3]. Much less attention is paid to the methodological foundations. However, getting the expected high results associated with digitalization is being delayed. This happens, first of all, due to the dominance in the educational paradigm of the still passive (objective) position of students. New forms of digital education are not sufficiently focused on individual requests and students' own activity (manifestation of their subjectival position), only modifying the forms of knowledge representation and educational control.

An ecosystem is a collection of all the elements that make up the human environment. However, as P. Luksha writes, if we talk about the ecosystem of collective learning, this is a broader concept: it is a learning community in which cooperation comes to the forefront. He makes a comparison with the biological ecosystem of an ant hill; every ant is important. By analogy, we can confidently assert that in the educational ecosystem, the role of everyone is extremely important.

Digitalization offers new formats for the exchange of knowledge, for example, changing the role of the teacher to its complete absence in educational and training virtual simulators, various options for distance education (online courses). Indeed, various computer systems for modeling and simulation of real processes make it possible to form both cognitive-type skills (to understand the essence of the processes) and motor-reflex actions (specific behavioral skills). Interactive Internet simulators are relevant as programs of independent mastering (or repetition) with simultaneous control of knowledge and skills. However, the use of trainers and simulators, as well as independent distance learning, requires developed educational motivation, a system of self-regulation and self-control. With their insufficient development and the absence of a teacher, these educational formats lose most of their advantages (personalization of the pace and volume of knowledge, simplification of control, etc.).

Compensation of teacher's absence has led, similar to digital organizations, to the development of models of the digital teacher as a digital worker. For example, the development of a digital assistant for interaction with the most active students [4] or educational chatbots (the Albert chatbot, which provides training through messengers and simulators with artificial intelligence, does not require the installation of special software, implemented in as an individual or group chatbot) [5]. 
Such a digital employee / digital assistant acts as a competent element of the social component of the ecosystem, including the educational ecosystem of the university. The digital worker doesn't need a rest, a break, a lunch, a sick-list, or vacation. He can quickly and clearly answer the questions provided by the script.

The technological design of a digital employee as an element of an eco-system is accompanied by the emergence of digital consciousness as an understanding by developers of the possibilities, consequences and limitations of the use of digital technologies, which can be both transformative and destructive depending on the point of view of the designer [6].

Considering that all types of connections between the components of the system are important for the ecosystem, we have paid attention to the quality of the social component. Surviving the digital revolution is possible only through social dialogue with new rules of interrelationships, a flexible system of effective interactions $[7,8]$.

So, we come to the need for a special organization of the environment as a component of the ecosystem. The analysis of educational interactions from the position of the peculiarities of the educational environment is revealed in the works of V.A. Yasvin [9]. The mastery of the developmental possibilities of the environment by a person is considered by V.A. Yasvin as the main psychological mechanism of the interaction of a person with the environment and as the content of the psychological design of a personality-developing environment.

As an environment for personal development and self-development of students in the work of A.V. Kaptsov, the role of the educational student group and emerging microgroups is outlined [10]. In the process of interpersonal communication and joint learning activities, changes occur in the intellectual and personal spheres of students. The study of E.I. Kolesnikova shows the influence of relationships in the study group on the dynamics of the level of psychometric intelligence, personal qualities and values during the period of study at the university [11].

In scope of ecopsychological approach $[12,13]$ six basic types of ecopsychological interactions between components «learner - teacher (educational environment)» are distinguished. Type of interaction is defined by role position of each component, where each partner by interaction can hold either subject or object position. According to the objective position, the authors distinguish object-object, object-subject, subject-object interaction. Components of system «learner - teacher (educational environment)» hold active role position in relationship to each other in subject-subject relations: subject-standalone, subjectcooperative and subject-generative subtype of interaction.

The main statements of the (ecopsychological) environmental approach were formulated long before digitalization, but they have not lost their relevance. Analysis and flexible adjustment to lifestyle, following the client in the process of digitalization of his lifestyle are an important part of digital transformation [8].

Along with the changes caused by digital transformation, at present human also inheres the fact that V.A. Petrovsky designates as reflected subjectivity [14]. He writes that it is impossible to be a person as a subject of communication without one or another degree of ideal representation (reflection) of a person in the other people's lives. That is, there is always an idea of a partner (including an ideal partner), an image of comfortable interaction. The existence of an individual, according to V.A. Petrovsky, appears as relatively autonomous (split off, independent) from himself, as the other being of the individual, or otherwise - his ideal existence (reflected subjectivity). The effects of the influence of the first are not limited to any, even significant from the point of view of the first individual, changes in the behavior and consciousness of the second, but those changes that are significant for the second (significant Other) are important. Among the methods of representation, both real interaction 
and communication are distinguished, as well as the materialized representations, which are of particular importance in the context of digitalization, the presentation of symbolic substitutions, objects, an avatar, a photograph, a phonogram of a voice, quasi-presence, an imaginary presence, etc.

The image of the "significant Other» launches an internal dialogue of the personality aimed at rethinking behavior strategies, expanding the range of possible ways of responding to a situation and developing new strategies. The study shows that the image of a «significant Other» as a symbolic representation of a significant person in a person's actual situation is the means that allows one to move from automated, rigid, non-voluntary responses to the emergence of a difficult life situation to a conscious, purposeful, flexible behavior, voluntary regulation of one's own emotions and methods of controlling [15].

It is important to use a stylistic approach to analyze the social component of the ecosystem from the position of ideas about the relationship and interaction between the subject and the environment $[16,17]$. The unit of analysis of the joint activities of the subjects is not individual subjects, but professional psychological groups, for example, the dyads «doctorpatient», «trainer-athlete», «teacher-student», «supervisor-subordinate» [17]. At the same time, fragments of interaction are investigated, both real «here and now» (intersubjective resources) and potential «there and then» (non-subjective resources), which focuses not on an individual subject, but on joint professional activity, taking into account the environmental factor.

Stable, invariable, generalized characteristics of style are formed from a potential set of components of joint activity of subjects by arbitrary choice. V.A. Tolochek defines such characteristics as the preferred «subjectively convenient conditions of activity», professionally determined systems of activity components (operational systems as the organization of its activity components specific to each style) and a specific active set of ideal objects (principles, criteria, etc.) ensuring the organization and regulation of the operating conditions («ideal regulators / type of organization») [17]. The styles of business communication are highlighted: first - formalization of interactions, minimization of cooperation, encouragement of partner's activity; the second is softness and evasiveness, distancing from a partner; third - firmness and distancing, perseverance, force confrontation; fourth - high activity and inconsistency, inflexibility, invisibility of the perspective of interactions; the fifth - liberal style; sixth - rigidity, distancing, focus on compromise solutions. The authors classify them as adaptive - non-adaptive, effective - non-effective for the studied organization [18].

Indices of effectiveness take on new meaning in the digital ecosystem. Changes of conditions of professional work in the digital ecosystem of the university are associated with the conditions for organizing the environment, which can be specifically rigidly and formally structured, or there are flexible, rigidly unstructured conditions (Agile-approach). Flexibility is noted as a progressive indicator for the ecosystem of the subjective convenience of system components when interacting [8].

In this regard, the style approach, as taking into account among the components subjectively convenient conditions of activity, seems to us relevant for the design of the social component of the ecosystem. Moreover, ideal regulators of activity [16] show researchers the «future» of the system, the subject's aspiration to activity.

On the example of the dyad «teacher-pupil» («trainer-athlete» in professional sport), it was revealed that the decisive factor of success is not the targeted «activity» of the subject itself, but the transformation of the «space of activity», the active organization by the subject of comfortable conditions and the tasks of this activity. V.A. Tolochek states that in reality the subjects plan, organize and successfully carry out activities within the framework of their 
subjectively acceptable space of activity, and not abstracting from the subjectively significant, realizing activities only in accordance with its «objective» conditions and requirements. On the contrary, going beyond the limits of a kind of subjectively convenient space of activity is associated with the failure of the subject [16].

In a longitudinal study, E.I. Kolesnikova, using the example of the dyad «studentteacher», revealed that students who build the image of a subjectively comfortable teacher as superior in terms of professionally important qualities have a more expressed development of psychometric intelligence, abstract thinking, higher academic performance in certain disciplines and average score per examinations, more intensive personal changes [19].

In general, it must be said that research on the aspect of a subjectively convenient partner in educational interaction is currently insufficient nowadays. When focusing on the technical solution to support digitalization processes, the social component of the educational ecosystem has not been sufficiently developed, including from the position of comfort, convenience for educational interaction in the dyad «student-teacher». These questions acquire particular relevance in connection with the transformation not only of the role, but also of the image of the teacher as an «agent of change».

Thus, in addition to such classic trends in the development of education as the organization of a developing educational environment, it is necessary to supplement with the direction related to digitalization in the field of creating a prototype of a digital employee as a digital twin of a teacher, taking into account the opinion of students about a teacher who is convenient for them. The study of students' ideas about the subjectively convenient style of the teacher's activity in the context of digitalization was the purpose of this work.

\section{Materials and Methods}

The study of conception about a convenient partner in the dyad «student-teacher» was carried out on three samples characterizing different stages of personal and intellectual development of students in one of the leading technical universities [10]. The first sample consisted of sophomore students (118 people, of which 62 were men), the average age is $18.2 \pm 0.3$ y.o., out of 21 students combining work with study, slightly more men - 12 people. The second sample is represented by fourth-year students ( 49 people, of whom 5 were men), the average age is $20.9 \pm 0.3$ y.o., 25 people work and study. The third sample consisted of second-year undergraduates selected according to the principle of succession and students with Bachelor's degree at the same university ( 68 people, of which 34 were men), the average age was 22.8 \pm 0.6 y.o. 48 people combine work and study, of which 21 are men, that is, girls have a more active life position at the beginning of their working career during training. Total 235 students.

The cross-sectional method was used, diagnostics was carried out simultaneously in all samples at the beginning of the academic year (October 2020). The overwhelming majority of the classes were teaching in a remote learning format due to the unfavorable epidemiological situation in the region. The blended learning format (prevailing online format in combination with face-to-face), we believe, has raised questions about the specifics of style preferences in communicating with teachers in the context of digitalization.

We assumed that style preferences could be influenced by the employment of students, since the influence of the professional employment environment is mixed with the influence of the educational environment. Therefore, we took into account information about the official work experience provided by the participants in the study. Each of the subsamples was divided into two parts and differences were revealed depending on the presence or absence of official work experience, as well as on gender. 
The main diagnostic technique was the questionnaire «Style of business communication» [17]. It consists of 40 questions, the answers to which characterize the frequency, or vice versa, the rare use of various components of style preferences. The answers, depending on the coincidence with the key of the methodology, show the respondent's preferences: a) subjectively comfortable conditions of activity (SCWC) - the first hierarchical level of organization of the style, determining the choice of environment conditions convenient for the subject, modes of activity; b) preferences of the components of the operational system (OS) - the second hierarchical level of style, i.e., specific cognitive, emotional and objective actions (communication actions) that mediate the interactions of subjects; c) ideal regulators or type of activity organization (IR or TAO), understood as the third, highest level of the hierarchical style, represented by the preference for different communication functions and behavior strategies. To assess the severity of the BCS components, the respondents were offered a five-point scale - from 0 to 4 points. The technique provides the ability to calculate the frequency of manifestation of certain functions, conditions, strategies and actions in business communication. It is possible to determine an individual profile and determine the average profile of the study sample, although the technique has been developed for the study of joint activities (a dyad, triad, micro-group, collective).

For diagnostics in this work, the questions of the research methodology (questionnaire «Styles of business communication» BCS) of V. A. Tolochek were transferred to the form of a questionnaire using the Google Forms service. One part of the questionnaire took into account the opinion about one's own style peculiarities of business communication in the range of interaction «student-teacher» [20]. Another part took into account the style features of a student-friendly partner in business communication in the dyad of interaction «studentteacher» [21].

The primary processing of the data made it possible to characterize the preferred styles on various samples of students, as well as to obtain style portraits of comfortable teachers at various stages of study at the university. Secondary data processing was carried out using mathematical and statistical methods (STATISTICA 10.0 package).

We hypothesized that differences in preferences for the components of communication and behavior of a comfortable teacher are interrelated with the personality traits, values, and self-regulation of students. The latter, as we have shown in [19], are predictors of competence development and academic success. To diagnose personality traits, a sixteen-factor questionnaire by R.B. Cattell (form C), test of axiological orientation of personality AOP 4.5.2 [22], questionnaire of the style of self-regulation of behavior SSB-M [23].

To identify the difference between the samples, we used one-way analysis of variance, the dependent variables were the individual components of the research questionnaire, representing both self-assessment and assessment of functions, conditions, strategies and ideal regulators of business communication in the dyad «student-teacher».

To identify the relationships, correlation analysis was used (the tau-Kendall rank correlation coefficient, since the verification of the primary data showed the deviation of most of them from the normal distribution law). Correlation analysis was carried out for the calculated value of the discrepancy between the self-esteem of style features with the assessment of a comfortable teacher by finding the arithmetic difference of raw points, the relative value in percentage and the frequency of discrepancies.

\section{Results}

The results of the one-way dispersing analysis of ANOVA / MANOVA are presented in Table 1 . The median values are given in accordance with the questionnaire scale: 0 - never 
used a component, 4 - always used. That is, the higher the value in the table row, the more often the style component is used in a particular selection / sub-selection and vice versa. An additional validation was carried out according to the Scheffe criterion between samples / subsamples; significant differences are marked in bold type in the table.

Table 1. Results of dispersing analysis for revealing differences in the components of the style of business communication in the dyad «student - comfortable teacher».

\begin{tabular}{|c|c|c|c|c|c|}
\hline № & Component & subsamples & $\begin{array}{l}\text { Sample } 1 \\
118 \text { people, } \\
62 \mathrm{~m} ., 21 \\
\text { workers }\end{array}$ & $\begin{array}{l}\text { Sample } 2 \\
49 \text { people, } 5 \\
\text { m., } 25 \\
\text { workers } \\
\end{array}$ & $\begin{array}{l}\text { Sample } 3 \\
68 \text { people, } 34 \\
\text { m., } \\
\text { workers } \\
\end{array}$ \\
\hline \multirow[t]{2}{*}{3} & \multirow[t]{2}{*}{ Long distance } & All & $2.2 *$ & 2.1 & $1.8^{*}$ \\
\hline & & women & $2.4 *$ & 2.2 & $1.8 *$ \\
\hline \multirow[t]{2}{*}{6} & \multirow{2}{*}{$\begin{array}{l}\text { Reliance on } \\
\text { argumentation }\end{array}$} & All & 3.2 & $3.5^{*}$ & $3.0 *$ \\
\hline & & men & $3.0 *$ & - & $3.9 * *$ \\
\hline 9 & $\begin{array}{l}\text { Information } \\
\text { exchange }\end{array}$ & All & $3.0 * *$ & $3.4^{* *}$ & 3.2 \\
\hline 10 & Evasion & All & 1.5 & $1.2 *$ & $1.7 *$ \\
\hline 19 & Close distance & Men & $2.4^{*}$ & - & $1.0 *$ \\
\hline \multirow[t]{3}{*}{21} & \multirow{3}{*}{$\begin{array}{l}\text { Organization of } \\
\text { space }\end{array}$} & All & 2.5 & $3.9 * *$ & $2.3 * *$ \\
\hline & & No work & $2.4^{* *}$ & $3.1 * *$ & $2.4 * *$ \\
\hline & & Women & 2.6 & 3.0* & $2.5^{*}$ \\
\hline \multirow[t]{3}{*}{22} & \multirow{3}{*}{$\begin{array}{l}\text { Using } \\
\text { documents }\end{array}$} & All & $2.2 * *$ & $2.8 * *$ & 2.4 \\
\hline & & No work & $2.2 * *$ & $3.0 * *$ & 2.9 \\
\hline & & Women & $2.3 * *$ & $3.0 * *$ & 2.6 \\
\hline \multirow[t]{2}{*}{23} & \multirow[t]{2}{*}{ Time fixing } & all & 2.2 & $2.4 * *$ & $1.9 * *$ \\
\hline & & No work & 2.0 & $2.4 * *$ & $1.5 * *$ \\
\hline \multirow[t]{2}{*}{24} & \multirow[t]{2}{*}{ Assistance } & all & 3.0* & $3.5^{*}$ & 3.0* \\
\hline & & No work & 3.0 & $3.5 *$ & $2.8 *$ \\
\hline 25 & $\begin{array}{l}\text { Interaction } \\
\text { management }\end{array}$ & No work & $2.5^{*}$ & $2.0^{*}$ & $2.4 *$ \\
\hline \multirow[t]{3}{*}{28} & \multirow[t]{3}{*}{ Low activity } & all & 1.4 & $1.9 * *$ & $1.3^{* *}$ \\
\hline & & No work & 1.5 & 2.0* & $1.4 *$ \\
\hline & & women & 1.5 & $1.8 *$ & $1.0 *$ \\
\hline \multirow[t]{2}{*}{31} & \multirow[t]{2}{*}{ Encouragement } & All & 3.0 & $3.4^{*}$ & $2.8 *$ \\
\hline & & Work & $2.7 *$ & $3.2 *$ & 3.1 \\
\hline 32 & Specific goals & All & $3.1 * *$ & $3.4^{* *}$ & $3.1 * *$ \\
\hline 33 & $\begin{array}{l}\text { Self-development } \\
\text { function }\end{array}$ & All & 2.9 & $3.2 * *$ & $2.6 * *$ \\
\hline 38 & $\begin{array}{l}\text { Confidential } \\
\text { conversation }\end{array}$ & Men & $2.2 * *$ & - & $1.2 * *$ \\
\hline 39 & $\begin{array}{l}\text { Means of } \\
\text { communication }\end{array}$ & No work & $2.4^{*}$ & 3.0* & 3.0* \\
\hline 40 & Clarity of tasks & All & $3.0^{* *}$ & $3.5^{* *}$ & 3.2 \\
\hline
\end{tabular}

Note. Differences with level $\leq 0.05$ are marked with *, with level $\leq 0.01$ marked $* *$ 
According to the results of Table 1, we can carry out two types of analysis: the revealed differences between samples and subsamples, as well as an analysis of the median value, which indicates how often (values of 4 and 3 points) or rarely (values of 0 and 1 points) are used style components. We note the most salient features by combining difference analysis and expression analysis.

Students prefer the following in the form of a comfortable teacher:

- among the operational systems of activity: the frequent use of reliance on arguments, facts (especially men in the senior year), the use of sources of information, encouragement and support, the setting of specific goals and criteria for the findings, the use of technical means of communication, assistance and setting clear goals. These differences are especially evident among senior students. At the same time, students do not believe that they need frequent confidential conversations and rigid time fixation of communication. It turns out that they set their own boundaries and develop their own style of temporary organization. There are also multidirectional, but essentially consistent results. For example, the choice of a distance with the possibility of choosing the use of a long distance, but also not close, which reflects, in our opinion, the concept of an optimal comfort zone (neither hot nor cold, but warm). Social partnership does not tolerate familiarity; it is truly a business-like and convenient interaction.

- subjectively comfortable conditions of activity include the frequent organization of physical space and exclude the low activity of the teacher in changing the conditions and situations of communication, which is especially characteristic of four-year students. This is probably due to the higher number of academic works requiring the advice of a teacher (course paper, preparation for a diploma paper), and in comparison, with undergraduates, they spend more time at the university. Such high requirements for a comfortable teacher are alarming. It is quite possible that we are faced with a potential tendency not to share responsibility for educational results, but to shift it onto the shoulders of a comfortable teacher.

- at the highest hierarchical level of the style organization - ideal regulators of activity, we note the expectation of students from the ideal teacher of frequent information, management of interactions and development of other people, as well as a rare postponement of the solution of the problem. Again, we are faced with the delegation of initiative from a student to a convenient teacher, although in order to complete the task as soon as possible. This does not fully meet the tasks of modern education, which presupposes the student's own activity and self-development and requires special attention.

Table 2 shows the results of the correlation analysis (tau-Kendall rank correlation coefficients). The variables were personality traits (personality traits according to the 16factor questionnaire $16 \mathrm{PF}$ R. Cattell, features of conscious self-regulation planning, modeling, programming, assessment, flexibility and independence, as well as pairwise opposite personal values of individuality - collectivity, self-development - stability, spiritual satisfaction - material well-being, traditions - creativity, life activity - achievements, determined in the spheres of life of the profession, education, family, social life and hobbies). The number of dependent variables included the coefficient of discrepancy, calculated as the number of nonzero values of the arithmetic difference between the self-assessment values and the values of the components of the comfortable teacher's style in relation to the total number of components. 
Table 2. The results of the correlation analysis of personality traits and the coefficient of discrepancy between self-esteem and the components of the style of business communication of the dyad «student - convenient teacher».

\begin{tabular}{|c|c|c|c|}
\hline $\begin{array}{c}\text { Samples } \\
\text { subsamples }\end{array}$ & $\begin{array}{c}\text { Sample } 1 \\
118 \text { people, } 62 \mathrm{~m} ., 21 \\
\text { workers }\end{array}$ & $\begin{array}{c}\text { Sample } 2 \\
49 \text { people, } 5 \text { m., } 25 \\
\text { workers }\end{array}$ & $\begin{array}{c}\text { Sample } 3 \\
68 \text { people, } 34 \text { m., } 48 \\
\text { workers }\end{array}$ \\
\hline Work & $\begin{array}{l}\text { G 16PF }(-0,33) \\
\text { Q3 16PF }(-0,35) \\
\text { The value of } \\
\text { education } \\
(-0,32)\end{array}$ & - & $\begin{array}{l}\text { M } 16 \mathrm{PF}(-0,24) \\
\text { O } 16 \mathrm{PF}(-0,24) \\
\text { The value of hobbies } \\
(0,28) \\
\text { The value of material well- } \\
\text { being }(0,26)\end{array}$ \\
\hline No work & $\begin{array}{l}\text { M } 16 \mathrm{PF}(0,22) \\
\text { The value of } \\
\text { individuality }(0,20) \\
\text { Regulatory flexibility } \\
(0,15)\end{array}$ & $\begin{array}{l}\text { G 16PF }(-0,42) \\
\text { Q3 16PF }(-0,32) \\
\text { The value of } \\
\text { collectivity }(-0,3) \\
\text { The value of creativity } \\
(0,49) \\
\text { Planning }(-0,34) \\
\text { Modelling }(-0,35) \\
\text { Self-dependence } \\
(-0,33)\end{array}$ & N 16PF $(-0,47)$ \\
\hline Men & $\begin{array}{l}\text { C 16PF }(0,17) \\
\text { I 16PF }(0,19) \\
\text { Planning }(-0,24)\end{array}$ & - & $\begin{array}{l}\text { The value of material well- } \\
\text { being }(0,27)\end{array}$ \\
\hline Women & $\begin{array}{l}\text { M } 16 \mathrm{PF}(0,43) \\
\text { The value of hobbies } \\
(0,22) \\
\text { The value of } \\
\text { individuality }(0,28) \\
\text { Regulatory autonomy } \\
(0,20)\end{array}$ & $\begin{array}{l}\text { MD } 16 \mathrm{PF}(-0,22) \\
\text { The value of } \\
\text { achievements }(0,22)\end{array}$ & $\begin{array}{l}\text { I 16PF }(0,34) \\
\text { M 16PF }(-0,29) \\
\text { Q3 16PF }(0,30) \\
\text { The value of hobbies } \\
(0,28) \\
\text { The value of the profession } \\
(-0,27) \\
\text { Programming }(-0,32) \\
\text { Regulatory autonomy } \\
(-0,26)\end{array}$ \\
\hline
\end{tabular}

Note. Significant correlation coefficients with a confidence level of $\leq 0.05$ are indicated.

Various relationships were revealed in the samples, which confirms the hypothesis about the influence of combining work and study at a university on style preferences in the image of a teacher. Among working sophomore students, a significant discrepancy between selfesteem and the style portrait of a comfortable teacher is associated with a decrease of norm control and self-control, as well as a devaluation of the sphere of education. Perhaps for these students a comfortable teacher, being more interested in the results of their training, compensates for their negligence, disorganization, performs a guardian and supervising role. Unemployed sophomores disagree more with increasing dreaminess, self-worth, and the ability to rebuild. Probably, the landmarks of such students are less consistent with reality than those of working students, although sophomores who indicated their professional employment are involved in the majority in low-skilled jobs. 
Fourth-year students combining work with study do not have significant relationships with discrepancies in perceptions; an acceptable reason may be inhomogeneity of the sample or the presence of nonlinear relationships. For non-working fourth-year students, the discrepancy increases along with a decrease of norm control and self-control, team values and planning abilities, perspective awareness and autonomy, with an increase in the value of creativity. One gets the impression that a comfortable teacher is personified with personal freedom, creativity, deviation from norms. He probably looks more like a playmate, a hobby partner, than an educational landmark and business interaction partner.

We noted that a number of identified relationships are characteristic of both sophomore and fourth-year students in terms of personality traits and some personal values. Understanding the limitation of the cross-sectional method, we made the apriorism that, perhaps, we are dealing with the transitivity property of the style organization, identified by V.A. Tolochek [17], when the formation of styles occurs under conditions of initial order.

Working undergraduate students differ more in self-esteem and esteem of comfortable teacher while increasing practicality and reducing anxiety, increasing the importance of the sphere of hobbies and the value of material well-being. Most likely, a comfortable teacher for them will provide material and mental confidence in the future. The discrepancy between non-working undergraduates is simply due to their naivety.

It should be marked that, in general, the discrepancy for all samples has the same tendency towards polarization of perceptions about a comfortable teacher in comparison with selfesteem. So, if students rarely use some component, then a comfortable teacher uses this component even less often, and vice versa, if students often use style components, then a comfortable teacher does it even more often. We also find out that the presence of additional professional employment leads to differences in the discrepancy between self-esteem and perceptions towards practicality and adequacy, while the absence of additional employment caused the discrepancy by naivety, disorganization and the search in a comfortable teacher for a leader who controls educational interaction.

Differences were also revealed by gender. The discrepancy among male sophomore students is associated with emotional stability, but kindness and a low ability to make life plans, and among male undergraduates with a high value of material well-being. Second-year female students disagree more with daydreaming and an increase in the values of hobbies and the value of individuality, while at the same time high planning independence. For fourthyear female students, the discrepancy is associated with an increase in the adequacy of selfesteem and an increase in the value of achievements. For female undergraduates, the relationship is inherently feminine, but at the same time practical and principled, with a high value of hobbies, a low value of the profession and regulatory autonomy. As we can see, the grounds for the discrepancy are different, and have both a material basis (senior students) and a spiritual basis (younger students). They can be opposite in essence (for example, regulatory autonomy and the factor of practicality-dreaminess in the female subsample for the 2nd and 6th years of study at a university).

\section{Discussion}

The findings indicate that it is convenient for students to work not in a situation of social partnership, cooperation, but in the position of an industrial paradigm, in the position of a follower, and not an active subject of their educational and life path. Therefore, the social partnership of a student and a teacher, embedded in the very essence of the educational ecosystem of a university, requires a rethinking of the importance of the social component and special psychological and pedagogical support. The student, in our opinion, may be 
technically ready for partnership, he has the initiative, ideas, appropriate motivation. A student can even be a leading partner, he can know and be able to even more than his teacher due to his preparedness, awareness for reasons of curiosity, outstanding abilities, giftedness, etc. Each teacher in his work has encountered such manifestations. But according to our observations, the student does not always show himself for several reasons, for example, the lack of confidence that the results of the work are sufficiently evaluated on his own scale, or the lack of psychological safety of the educational environment with this partner. In conversations with students, they formulate approximately such activity-limiting statements as «why try, no one needs it», «you do, you do, and you don't get anything for it», «if you ask a question, it will be worse for you» etc.

We left aside the issues of motivation and focused on the technical side of ensuring interactions in the social component of the educational environment of the university. We believe that the conditions of digitalization provide opportunities for a qualitative redistribution of the roles of a student and a teacher through the use of emerging advantages. First of all, due to the use of digital analogs from other spheres of life of subjects of education, for example, gamification methods. The study [24] discusses the impact of video games on academic performance and shows that along with negative effects, there is also a positive one associated with cognitive development, an increase in the speed of processing visual content and typing, and hand-eye coordination. So, the enrichment of the content of the interaction between the teacher and the student using digital technologies will not create obstacles in learning.

The general distribution of virtual assistants (prompts and changes of characters in video games, voice and text bots) sets the basis for the introduction of digital workers into the educational process. They can be integrated into the functionality of the student's personal account to receive prompt answers to the technical support of the educational process, or be present in the form of a digital employee who assumes partly or completely the role of a teacher.

Debatable question is the criteria for the classification of roles and tasks as the basis for the development of algorithms for digital support of the teacher's role.

I.V. Lebedev proposes a level model of social and psychological conditions for effective digitalization in an organization, which is characteristic of the systems approach. The criteria for classifying the social component are personal, group and intergroup levels in combination with aspects of social conditions and managerial situations [25]. The problem of reconciling the architecture of interaction in the system as a proportion of natural and artificial intelligence in the dyad «executor-agent» is considered in [26].

We will discuss and summarize the main elements of these models in terms of the style approach and the organization of subjectively convenient educational interactions. In search of an increase in the effectiveness of the performance of the role of a teacher in the educational process, we will formulate criteria for recommendations for the design of a digital employee. We summarize the criteria that separate the functionality of a digital and nondigital teacher in Table 3. The connection to the studied style of business communication in the table is marked with numbers (the connection to table 1 is indicated by (1), the connection to table 2 is indicated by (2)). AI in the table and further in the text denotes «artificial intelligence» implemented in the form of special software. 
Table 3. Recommendations for designing a digital employee based on the style approach in the dyad «student-comfortable teacher».

\begin{tabular}{|c|c|c|}
\hline Criterion & Teacher - bot & Teacher- human being \\
\hline $\begin{array}{l}\text { Communication, supply } \\
\text { of arguments, facts (1) }\end{array}$ & $\begin{array}{l}\text { A given set of actions, standard } \\
\text { procedures }\end{array}$ & $\begin{array}{l}\text { Professional competence, } \\
\text { erudition of the teacher }\end{array}$ \\
\hline Clarity of goals (1) & $\begin{array}{l}\text { A clear statement of the task } \\
\text { and adherence to the } \\
\text { established deadlines }\end{array}$ & $\begin{array}{l}\text { Possible irregularity due to } \\
\text { «human factor» }\end{array}$ \\
\hline $\begin{array}{l}\text { Presentation of } \\
\text { information (1) }\end{array}$ & $\begin{array}{l}\text { Hyperlinks for additional } \\
\text { information, gamification, } \\
\text { visualization, the ability to } \\
\text { connect additional sensory } \\
\text { sources (augmented reality), } \\
\text { reliable and predictable, when } \\
\text { using AI, individual training } \\
\text { recommendations }\end{array}$ & Teacher's didactic competence \\
\hline $\begin{array}{l}\text { Trainee activity } \\
\text { management (1), (2) }\end{array}$ & $\begin{array}{l}\text { Tactical tasks, it is possible to } \\
\text { use several versions with the } \\
\text { student's choice of the level of } \\
\text { difficulty, the desired } \\
\text { assessment, the level of } \\
\text { competence. When using AI, } \\
\text { expanding the range, } \\
\text { forecasting and selecting the } \\
\text { optimal options for the student }\end{array}$ & $\begin{array}{l}\text { The strategy of the educational } \\
\text { route, forecasting the result, } \\
\text { often based on pedagogical } \\
\text { skills, experience, intuition }\end{array}$ \\
\hline $\begin{array}{l}\text { Answer to question, } \\
\text { problem (1) }\end{array}$ & $\begin{array}{l}\text { Without delay with appropriate } \\
\text { technical conditions (Internet } \\
\text { availability, computer speed) }\end{array}$ & $\begin{array}{l}\text { Timeliness of response is not } \\
\text { guaranteed }\end{array}$ \\
\hline $\begin{array}{l}\text { Counsultations and } \\
\text { assistance (1), (2) }\end{array}$ & $\begin{array}{l}\text { On a twenty-four-hour basis in } \\
\text { the area specified by the script, } \\
\text { the use of AI expands the } \\
\text { possibilities of self-learning of } \\
\text { the bot }\end{array}$ & $\begin{array}{l}\text { Appointed / convenient } \\
\text { scheduled hours }\end{array}$ \\
\hline $\begin{array}{l}\text { Encouragement, support, } \\
\text { emotional connection ( } 2 \text { ) }\end{array}$ & $\begin{array}{l}\text { Standard, regular, as part of the } \\
\text { script, when using AI, the } \\
\text { range expands }\end{array}$ & $\begin{array}{l}\text { Non-standard irregular forms } \\
\text { of individual severity } \\
\text { depending on auto- and } \\
\text { sociopsychological competence }\end{array}$ \\
\hline $\begin{array}{l}\text { Changing the content, } \\
\text { structure of educational } \\
\text { material (1) }\end{array}$ & $\begin{array}{l}\text { Hardly predetermined by the } \\
\text { developer's script, the context } \\
\text { does not affect, when using the } \\
\text { AI, the bot self-learning }\end{array}$ & $\begin{array}{l}\text { Flexible, variable, the context } \\
\text { affects, possibly in several } \\
\text { focuses at the same time with } \\
\text { the appropriate competencies }\end{array}$ \\
\hline $\begin{array}{l}\text { Time regulation of } \\
\text { learning processes (1), } \\
\text { (2) }\end{array}$ & $\begin{array}{l}\text { Model time. Easily feasible, } \\
\text { controllable, individual rates } \\
\text { are possible depending on the } \\
\text { scenario. When using AI, } \\
\text { individual style }\end{array}$ & $\begin{array}{l}\text { Real time. In a group it is } \\
\text { difficult to accompany the } \\
\text { individual pace of the learner, } \\
\text { especially in the case of } \\
\text { outliers (leading and lagging). } \\
\text { Vulnerable spot - teacher self- } \\
\text { organization and motivation }\end{array}$ \\
\hline
\end{tabular}




\begin{tabular}{|l|l|l|}
\hline $\begin{array}{l}\text { Organization of joint } \\
\text { activities (1) }\end{array}$ & $\begin{array}{l}\text { Virtual group communication } \\
\text { scripts, mechanistic approach }\end{array}$ & $\begin{array}{l}\text { The presence of «live» } \\
\text { communication }\end{array}$ \\
\hline Control (2) & $\begin{array}{l}\text { Regular, with grading and } \\
\text { standard feedback for } \\
\text { repetitive, monotonous, high- } \\
\text { volume tasks }\end{array}$ & $\begin{array}{l}\text { The influence of the human } \\
\text { factor on the frequency and fact } \\
\text { of assessment (effects of } \\
\text { fatigue, sympathy or antipathy, } \\
\text { non-impartiality, possible } \\
\text { inadequacy) }\end{array}$ \\
\hline $\begin{array}{l}\text { Distance, respect of } \\
\text { boundaries (1) }\end{array}$ & $\begin{array}{l}\text { The ability of control from the } \\
\text { learner, the value of } \\
\text { individuality }\end{array}$ & $\begin{array}{l}\text { Teacher's personal script, } \\
\text { conflictological competence }\end{array}$ \\
\hline $\begin{array}{l}\text { Comfort, overall } \\
\text { convenience (1) }\end{array}$ & $\begin{array}{l}\text { Competent selection of the } \\
\text { interface and features of the } \\
\text { organization of teaching } \\
\text { materials }\end{array}$ & $\begin{array}{l}\text { Dependance on the level of the } \\
\text { teacher's professional } \\
\text { competence, his attitude } \\
\text { towards communication }\end{array}$ \\
\hline generalization & $\begin{array}{l}\text { High speed of data processing, } \\
\text { transparency of assessments, } \\
\text { independence from time and } \\
\text { place of training }\end{array}$ & $\begin{array}{l}\text { Solving unique and poorly } \\
\text { formalized problems, in } \\
\text { conditions of high uncertainty, } \\
\text { requiring creative approaches }\end{array}$ \\
\hline Advantages & $\begin{array}{l}\text { Inability to solve unique and } \\
\text { poorly formalized problems } \\
\text { Initial time for training }\end{array}$ & $\begin{array}{l}\text { Low data processing speed, } \\
\text { «human factor» }\end{array}$ \\
\hline \multicolumn{2}{|l|}{} \\
\hline Limitations
\end{tabular}

It's natural, this table does not include all the tasks of a digital employee. Based on the results of our research, we note that a digital teacher in a number of tasks will be more effective than a «live teacher». For example, the programmed activity of a digital teacher, frequent informing, management of interactions will satisfy the expectations of students to delegate the initiative to a comfortable teacher.

The authors' experience of remote work due to the pandemic suggests that a complete transition to distance learning, even a forced one, deprives students of many opportunities to communicate with a real teacher. But the majority of teachers faced many problems, e.g., with violation of hygienic standards for working with a computer, since in the conditions of distance learning, the teacher's working day was stretched more than one and a half times.

The presence of a digital assistant would make possible to turn harmful working conditions into acceptable or optimal ones, to get rid of routine. A digital assistant can be trusted to perform repetitive, routine, data-intensive tasks. For example, assign a task (enter into the educational information system, attach files to the student's personal account, check student attendance, timeliness of work completion by awarding additional points, express words of approval after students have completed their work, give the student a varied autoanswer, feedback on the task).

The digital assistant will especially help at the stage of skill formation in the control of the performed exercises (automatically remind about the end of the deadlines for the delivery of work), prompts in case of difficulties, scoring, solving typical tasks of classical training. The script can foresee the possibility of psychological support for the student (statements «You are great, you have mastered the stage ..., a little more and you are a qualified specialist»).

The provision of subjectively convenient conditions, it seems to us, will be successfully complemented by giving the teacher - bot humanity - by taking into account and including in 
the ontological graph the tasks of the user's personal preferences (character's selection, elements of gamification). Preferences of a convenient partner can take into consideration various scripts for the ratio of activity, pace, volume, behavior of the teacher-bot. We should especially note the possibility of expanding the capabilities and self-learning of the bot, e.g., supplementing scripts and forecasting the difficulties of mastering educational material when using AI.

It is possible to predict new problems in the development of a digital teacher: issues of joint functioning of subjects of teachers - executors and agents - robots, teaching chat bots as a virtual assistant of a teacher or a whole integrated team. Human-computer interaction puts forward new requirements for the qualifications of designers who, in cooperation with the customer - the head of the corresponding hierarchical level of the ecosystem, must be able to formulate requests for an intelligent agent at various levels of abstraction, effectively interact with an intelligent agent in achieving the set goals, train new technological skills and learn by yourself, improve the interface of interaction with AI, make joint decisions with $\mathrm{AI}$ in conditions of uncertainty, search for ways of improving processes to increase their efficiency.

The improvement of digital assistants leads to the issue of continuous professional development of teachers, both from the technical side and personal and professional development.

The introduction of digital assistants / doubles of the teacher into the educational process, which will undoubtedly happen in the near future, is a sensitive process that requires additional research and fine-tuning of educational interactions in the dyads "student-botteacher», «real teacher-teacher-bot» with the generalized name of the «agent - executor» model.

We also see the prospect of continuing research for the development of prototypes of digital employees, chat bots in digital organizations of a different profile. Including the development of systems for training and retraining of personnel at the enterprise through primary psychodiagnostics and subsequent design, taking into account the «individual adjustment» of digital employees according to the criterion of human convenience.

\section{Conclusions}

In modern conditions, the university appears before us as an educational eco-system in which all components and interactions between them are important. Digitalization, acting as the most important trend in the development of education, poses challenges to both the technological and social components. And if technological support is given priority funding and attention, then the social component is often left aside in the design of education systems. Discussion of insufficient attention to the social component of the ecosystem led us to the need to study the features of educational interaction in terms of styles of business communication in the dyad «student-teacher» and its convenience for the student. It is noticed that the preferences, which are formed from a set of components in the images of activity, impel the subject to the future. Such active organization by the subject of convenient conditions and tasks of this activity, in the authors' opinion, leads to the successful implementation of activities precisely within the framework of his subjectively acceptable space of activity.

We have stated that the actualization of the importance for the convenience of educational partnership of some components in comparison with others is interrelated with personal characteristics. To the greatest extent, this concerns personality traits (self-control and normative control, practicality, self-confidence), personal values (the value of the profession, education, hobbies, the value of individuality, material well-being), regulatory flexibility and 
independence. Differences in the preference of students for distance, delegation of initiative, degree of activity, spatial and temporal organization of business communication in the dyad «student-convenient teacher» were revealed. There is a polarization of self-esteem and perceptions about a comfortable teacher, e.g., if the more sociable student, the more sociable comfortable teacher.

Based on the style approach and the organization of subjectively convenient conditions for activity and a comfortable teacher, criteria have been developed that separate the functionality of a digital and non-digital teacher, suitable for creating a prototype of a digital employee in the educational ecosystem.

The study is executed at financial support RFBR, grant № 19-013-00550: «Styles of business communication: space and interaction strategies, subject's success resources».

\section{References}

1. A.V. Ivaschenko, A.V. Krivosheev, T.V. Nikiforova, Pragmatic model for human role definition in mixed intelligence solutions, In: Proceedings of the 4th annual science fiction prototyping conference, March 23 - 25, 2019, Ghent, Belgium 19 - 23 (2020)

2. P. Luksha, Spencer-Keyes Jessica, Cubista Joshua, Moscow School of Management SKOLKOVO and Global Education Futures. (2020). http://learningecosystems2020.globaledufutures.org/\#learning.

3. J.V. Lopukhova, E.D. Makeeva, Advances in Intelligent Systems and Computing 917, 514-524 (2019) doi.org/10.1007/978-3-030-11935-5_49.

4. HSE website. https://it.hse.ru/digitalreport/digital_assistants.

5. Platform for distance training of new generation skills Robot Al-bert. https://robotalbert.com/ last accessed 2021/01/22.

6. T. Saarikko, H. Westergren, T. Blomquist, Business Horizons 63(6), 825-839 (2020) doi.org/10.1016/j.bushor.2020.07.005.

7. J. Mas, A. Gómez, Technological Forecasting and Social Change 162, (2021) doi.org/10.1016/j.techfore.2020.120349.

8. Y. Xu, T. Koivumäki, Computers in Human Behavior 95, 307-314 (2019) doi.org/10.1016/j.chb.2018.10.021.

9. V.A. Yasvin, Psychology, Journal of the Higher School of Economics 17(2), 295-314 (2020) doi: 10.17323 / 1813-8918-2020-2-295-314.

10. A.V. Kaptsov, Personal and intellectual development of students in the conditions of the study group of a modern university (Publishing house «Samara Scientific Center of the Russian Academy of Sciences», Samara, 2011)

11. E.I. Kolesnikova, T.V. Kolesnikova, Review of European Studies 7(6), 108-115 (2015) doi: 10.5539/res. v7n6p108.

12. V.I. Panov, Ecopsychology: Paradigmal search (Psychological institute of the RAS; Nestor-Istoriya, M., SPb, 2014).

13. V.I. Panov, I.V. Plaksina, Analysis of ecopsychological types of interaction in system «learner-teacher», In: International Conference on Psychology and Education (ICPE 2017), 282-289 (2017) doi.org/10.15405/epsbs.2017.12.28.

14. V.A. Petrovsky, T.A. Nestik, Russian Academy of Science. Social and economic psychology 5(1) (17), (2020) doi: 10.38098/ipran.sep.2020.17.1.011.

15. T.S. Taburova, Bulletin of Altai State University 2(1), 66-69 (2011) 
16. V.A. Tolochek, The problem of styles in psychology: a historical and theoretical analysis (Institute of Psychology RAS, Moscow, 2013).

17. V.A. Tolochek, Styles of activity: a resource-based approach (Institute of Psychology RAS, Moscow, 2015)

18. V.A. Tolochek, V.V. Vilches-Nogerol, L.A. Sizova, Journal of the Belarusian State University. Philosophy. Psychology 1, 67-81 (2020).

19. E.I. Kolesnikova, Bulletin of the Samara Humanitarian Academy. Series «Psychology» 1(19), 3-17 (2016)

20. Questionnaire for a student to assess their own style of business communication in the dyad of interaction «student-teacher», Part 1. https://docs.google.com/forms/d/e/1FAIpQLSf69RmvwzCI6lgBFrCRTF3b3IrN5rh\&E oLYU49xJfu5oGb8-4w $=1 \& \mathrm{flr}=0$.

21. Questionnaire for assessing the teacher's student-friendly style of business communication in the student-teacher interaction dyad, Part 2. https://docs.google.com/forms/d/e/1FAIpQLSfWu7AJ0d2E1d9jd_h8chtUBbTiST-3 DCbmhJgriLHJq $=1 \&$ flr $=0$.

22. A.V. Kaptsov, Psychological axiometry of personality and group (Samlyuksprint, Samara, 2015)

23. V.I. Morosanova, I.N. Bondarenko, Diagnostics of human self-regulation (CogitoCenter, Moscow, 2015)

24. G.U. Soldatova, O.I. Teslavskaia, Journal of Modern Foreign Psychology 6(4), 21-28 (2017) doi: 10.17759/jmfp.2017060402 (In Russ.; Abstr. in Engl.).

25. I.M. Lebedev, Social and psychological conditions for the implementation of digitalization in construction, $\mathrm{PhD}$ Thesis, (Mytishchi, 2019)

26. A.V. Ivaschenko, A.R. Diyazitdinova, A.V. Krivosheev, T.V. Nikiforova, Information Technology 18(1), 68 - 76 (2020) doi: 10.18469/ikt.2020.18.1.11. 